\title{
Toxicity of Zinc Oxide Nanoparticles in Lung Tissue After Repeated Oral Administration
}

\author{
${ }^{1}$ Ataollah Shokouhian, ${ }^{1}$ Saman Soheili, ${ }^{1}$ Saeed Moradhaseli, ${ }^{1}$ Leila Fazli, \\ ${ }^{2}$ Mehdi Shafiee Ardestani and ${ }^{3,4}$ Masoud Ghorbani \\ ${ }^{1}$ Department of Biology, Faculty of Science, Payame Noor University, Tehran, Iran \\ ${ }^{2}$ Department of Nanomedicine, Faculty of Pharmacology, Tehran University of Medical Sciences, Iran \\ ${ }^{3}$ Department of Biochemistry, Microbiology and Immunology, \\ Faculty of Medicine, University of Ottawa, Ottawa, Ontario, Canada \\ ${ }^{4}$ Department of Microbiology and Immunology, Pasteur Institute of Iran, Tehran, Iran
}

Received 2013-09-28, Revised 2013-10-05; Accepted 2013-10-21

\begin{abstract}
Pathological experiments should be considered following oral administration of $\mathrm{ZnO}$. Effect of different doses of $\mathrm{ZnO}$ nanoparticle on $\mathrm{LDH}$ in oral method showed significant differences in control group $(\mathrm{p}<0.05)$ at high dose. Levels of IgG, TNF- $\alpha$ and IL-6 also elevated after administration of ZnO. The level of GSH decreased significantly. Lung damages included hyperemia and bleeding, atelectasis, light emphysema, pribronchiolitis, perivasculitis of lymphocyte in intensive level, pneumonia and increased secretion of exudates into bronchial. There was a significant difference in perivasculitis and pribronchiolitis among different doses of $\mathrm{ZnO}$ as compared with the control group $(\mathrm{p}<0.05)$. The result of this study showed that increasing doses of nanoparticles could cause significant damages to the lung tissue and to increase LDH, IgG, TNF- $\alpha$ and IL-6 and emphasizes that exposure to high concentration of ZnO could cause irreversible damages to different organs including lung and threaten the human health. This finding could be important as a health hazard to those who are in continuous exposure to $\mathrm{ZnO}$ nanoparticles.
\end{abstract}

Keywords: Zinc Oxide Nanoparticle, Oral Administration, Lung Tissue, Ldh Enzyme

\section{INTRODUCTION}

Nanomaterials have a great many medical applications which are growing rapidly to lead the widescale production and application of engineered Nanoparticles (NPs). Extension of nano engineering to the formation of fibers, sheets and volume-filling materials such as gels, networks and scaffolds as well as other none medical products such as cosmetics, sunscreens and food products are increasing. However, extensive usage of them may cause unwanted damages and toxicity to the living cells due to the increased surface reactivity of NPs. Nanoparticles have one dimension that measures 100 nanometers or less. The properties of many conventional materials will be changed when they are in nanoparticle form. This is typically because nanoparticles have a greater surface area per weight than larger particles which make them to be more reactive to some other molecules. Nanoparticles are used or being evaluated for use in many fields. In recent years $\mathrm{ZnO}$ nanoparticles have been used in different industrial sectors such as medicine, cosmetic materials (Golovko et al., 2007; Matsuyama et al., 2013), concrete (Demming, 2013), anti bacterial (Li et al., 2007; Chen et al., 2010), textile and automotive industries. Therefore, pathological experiments should be essentially considered. Significant features of nanoparticles in different industries correspond to their small size, although this characteristic has harmful effects on human health (Dubois and Nuzzo, 1992). Today, increasing applications of nanotechnology employed in sciences such as physics, chemistry and biology (Masciangioli and Zhang, 2003), could increase its toxicity and destructive effects on environment and human body. Measuring the Lactic Acid ology and Immunology, Pasteur Institute of Iran, Tehran, Iran Tel: +98-261-6102999 Fax: +98-261-6102900 
Dehydrogenase (LDH) levels helps to diagnose lung diseases, lymphoma, anemia and liver disease. They also help to determine how well chemotherapy is working during treatment of lymphoma. LDH is an enzyme that helps to produce energy (Feron, 2009).

Nanoparticles can enter the human body through different routes such as inhalation, ingestion and injection (Koeneman et al., 2010). They may then be translocated to blood causing adverse biological reactions in several organs, which are considered to be the secondary major sites of interaction (Johnston et al., 2010). The lungs are particularly susceptible to xenobiotics because of its high blood supply and its ability to concentrate toxins. Alteration of the total glutatahione GSH level in cells can be considered an indication of adaptive response to cell to oxidative damage. $\mathrm{ZnO}$ nano particles at high concentrations significantly decreased the lung GSH level compared with control group, which indicates functional damage to the lung tissues.

Therefore, consistent with these results proved that Nano-ZnO particles made hepatotoxicity to this animal model. It is suggested that $\mathrm{ZnO}$ nanoparticles should be applied with more precautions in relevant industries and also occupational health surveillance should be necessarily considered.

The objective of this study was to assess bronchial cell responses to the manufactured NPs to show their potential toxic biological effects.

\section{MATERIALS AND METHODS}

All animal protocols were reviewed and approved by the University of Payame Noor Iran Animal Care Protocol Review Committee; protocol number PN-1392/3.

Fourty female Wistar rats, all 8 weeks of age, weighed 250-300 g, were used in this study. The rats were obtained from the Experimental Animal Care Center, Pasteur Institute of Iran. They were housed individually in stainless steel mesh cages and were acclimatized before start of the experiments under standard conditions for a period of two weeks. The environmental conditions were set by adjusting the temperature at $22 \pm 1^{\circ} \mathrm{C}$ including a relative humidity of $60 \%$ and a $12 \mathrm{~h}$ light/dark cycle. All rats had free access to chow food (Behparvar Co, Tehran, Iran) and water. They were fed daily with different doses of $\mathrm{ZnO}$ nanoparticle. This study was carried out according to the standard guidelines approved by the animal care and use committee.

\subsection{Optimization of Dosage}

Animals were randomly divided into 4 groups. A Negative control group was fed with saline alone. Three other groups designated at low dose group (100 mg $\mathrm{kg}^{-1}$ ), middle dose group (200 mg kg-1) and high dose group ( $400 \mathrm{mg} \mathrm{kg}^{-1}$ ) respectively. All of them were fed with $2 \mathrm{~mL} /$ day $\mathrm{ZnO}$ nanoparticle by oral gavage for 14 days. All rats were monitored daily for any abnormal behavior and possible appearance of symptoms.

At the end of the treatments, all rats starved over night and were euthanized on the next day to determine the toxicity through examination of biochemical and histological analysis.

\subsection{Characterization of Zinc Oxide Nanoparticles}

$\mathrm{ZnO}$ Nanoparticles were purchased from FIDENA (Navara, Spain). A colloid solution with a concentration of $500 \mathrm{mg} \mathrm{mL}^{-1}$ in normal saline was then prepared. The size and shape of the nanoparticles were examined by field emission scanning electron microscopy FE-SEM using a High Resolution SEM with Charge Compensation System (Mod. Ultra Plus of Carl Zeiss) (Fig. 1).

The average diameter of the synthesized $\mathrm{ZnO}$ was about $20 \mathrm{~nm}$. The required doses of $\mathrm{ZnO}$ were then prepared with the following concentrations as 100, 200 and $400 \mathrm{mg} \mathrm{mL}^{-1}$ in saline.

\subsection{Experimental Animal and Diet}

\subsubsection{Biochemical Exprimentas and Parameters Measurement}

Blood samples were collected via the tail vein prior each gavage everyday to evaluate the plasma $\mathrm{ZnO}$ nanoparticle concentration. The blood samples were centrifuged at $3000 \mathrm{rpm}$ for $15 \mathrm{~min}$ at $4^{\circ} \mathrm{C}$ to obtain the serum for measuring the concentration of LDH enzymes using an auto-analyzer (BT 3000 plus Biotecnica Italian co).

\subsection{Determination of Lactate dehydrogense Activity}

Lactate Dehydrogenase (LDH) activity was measured using an LDH kit (Poite Scientific, Lincolu Park, MI, USA). One hundred microliter of serum was used for analysis. LDH catalyzed the oxidation of lactate to pyruvate with simultaneous reduction of $\mathrm{NAD}^{+}$to $\mathrm{NADH}$. The rate of $\mathrm{NAD}^{+}$reduction was proportional to $\mathrm{LDH}$ activity in the rat blood. Absorption was measured at $340 \mathrm{~nm}$ using a Beckeman DU-640B spectrophotometer. 


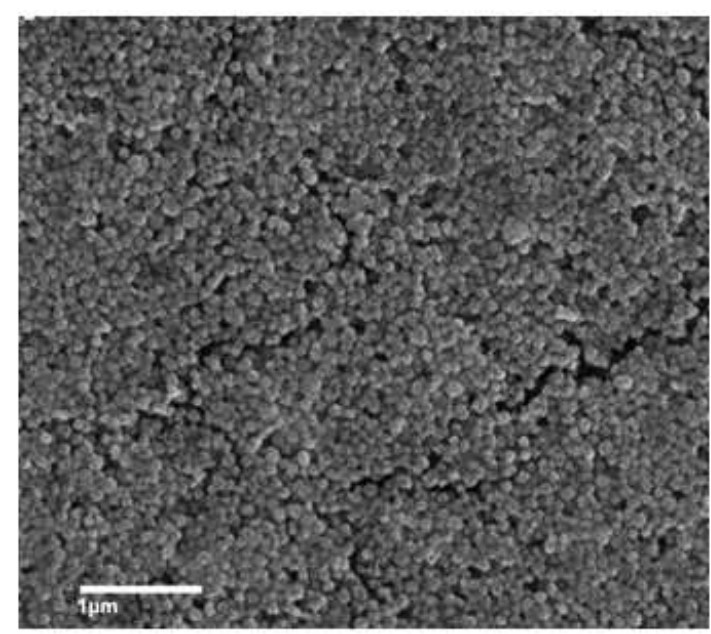

Fig. 1. FE-SEM picture of $\mathrm{ZnO}$ nanoparticles using a high resolution SEM with charge compensation system (Mod. Ultra Plus of Carl Zeiss)

\subsection{Measurement of Reduced Gluthatione (GSH) in Lung}

Level of acid-soluble thiols and reduced GSH in the lung tissue were determined by calorimetry assay at 412 nm (Moron et al., 1979). Lung tissue was homogenized in serine borate buffer $(100 \mathrm{mM}$ Tris- $\mathrm{HCl}, 10 \mathrm{mM}$ boric acid, $5 \mathrm{mM}$ L-serine, $1 \mathrm{mM}$ DETAPAC, pH 7.5). Homogenate were precipitated with trichloroacetic acid and centrifuged. The supernatants were then used for measurement of protein thiols (Protein-SH) expressed as $\mu \mathrm{mol} / \mathrm{mg}$ wet tissue.

\subsection{TNF-a Assay}

The concentration of TNF- $\alpha$ in serum was determined using commercially available enzyme-linked immunosorbent assay ELISA kits according to its manufacturer instructions (DuoSet kits, R\&D Systems; Minneapolis, MN, USA) Level of IL-6. The IL-6 levels were measured by ultra-sensitive ELISA (Quantikine HS Human IL-6 Immunoassay; R\&D Systems, Minneapolis, $\mathrm{MN}$ ) with an analytical CV of $6.3 \%$ and a detection level of $0.04 \mathrm{pg} \mathrm{mL}^{-1}$ (Kaden, 2007).

\subsection{Total IgG}

The level of total IgG was quantified in serum by sandwich ELISA using goat anti-ratIgG (Kirkegaard and Perry Laboratories, Inc., Gaithersburg, MD). Rat IgG antibody (Sigma Chemical Co., St.Louis, MO) was used as the standard. Goat anti-rat IgG peroxidase conjugates were diluted 1:250 in PBS/BSA (from Kirkegaard and
Perry Laboratories, Inc.) and used as detecting antibodies. The antibody-Antigen reaction was then detected after incubating the reaction with a chromogenic substrate (2,2'-azino-di[3-ethylbenzthiazoline sulfonate]) (ABTS; Kirkegaard \&Perry Laboratories, Inc.) for $15 \mathrm{~min}$ in dark followed by reading the optical density at $405 \mathrm{~nm}$ using an automated ELISA plate reader (Bio-Rad, USA) and immunoglobulin concentrations were determined by comparison of sample color development to standard curves (Kineticalc, Bio-tek Instruments, Inc).

\subsection{Histological Analysis}

At the end of study, rats were anesthetized with ketamine and xylazin and samples of lungs were dissected and fixed in 4\% formaldehyde solution for 24 hours. They were then dehydrated in 30, 50, 70, 90 and $100 \%$ ethanol respectively and cleared in xylene and embedded in paraffin. Paraffin blocks were later sectioned into $5-\mu \mathrm{m}$ thickness and fixed on glas slides. They were then rehydrated wit $+\mathrm{h}$ descending concentration of ethanol and subjected to staining with hematoxylin and eosin (H\&E) and examined under a light microscope.

\subsection{Statistical Analysis}

Data are presented as mean \pm S.D. Statistical analysis was performed using an Instat-3 computer program (Graph pad software Inc, San Diego, CA). One way Analysis of Variance (ANOVA) followed by Bonferroni multiple tests was used to determine the differences between means of different groups. The level of significance was set at $\mathrm{p} \leq 0.05$.

\section{RESULTS}

In the present work we demonstrated that the administration of $\mathrm{ZnO}$ nanoparticles significantly elevated $(\mathrm{p}<0.001)$ serum inflammatory markers such as (TNF- $\alpha$ and IL-6) levels in a dose dependent manner as compared with the control animals (Table 1). Moreover, Oral administration of $\mathrm{ZnO}$ nanoparticles significantly increased $(p<0.001)$ the serum IgG level in all doses $(\mathrm{p}<0.001)$ (Fig. 2).

All rats survived throughout the experimental period without exhibiting any abnormalities. The rats did not show any symptoms externally. $\mathrm{ZnO}$ nanoparticles increased the serum level of LDH in high dose group (400 $\mathrm{mg} \mathrm{kg}^{-1}$ ) to the highest level as compared with other groups. Therefore, by increasing the concentration of $\mathrm{ZnO}$ nanoparticle, the level of LDH enzyme in blood was affected significantly (Table 1). 
Ataollah Shokouhian et al. / American Journal of Pharmacology and Toxicology 8 (4): 148-154, 2013

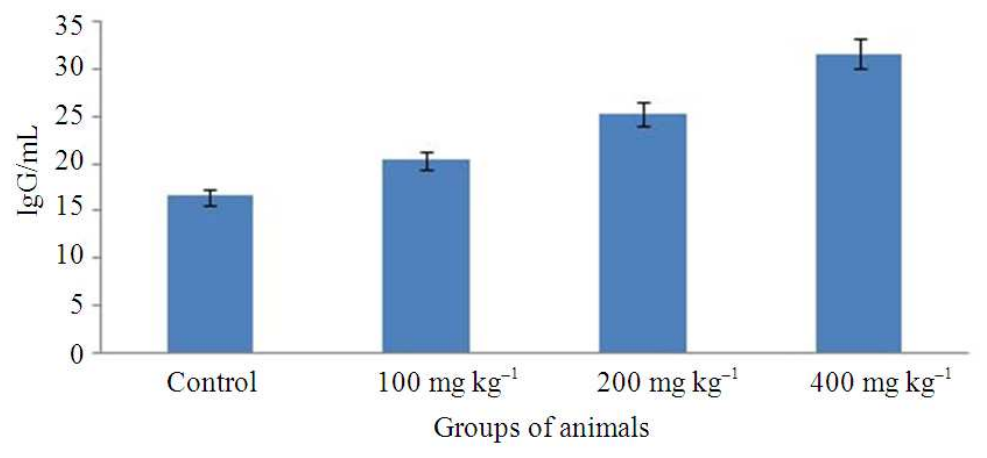

Fig. 2. Serum IgG levels after oral administration of $\mathrm{ZnO}$ nanoparticles

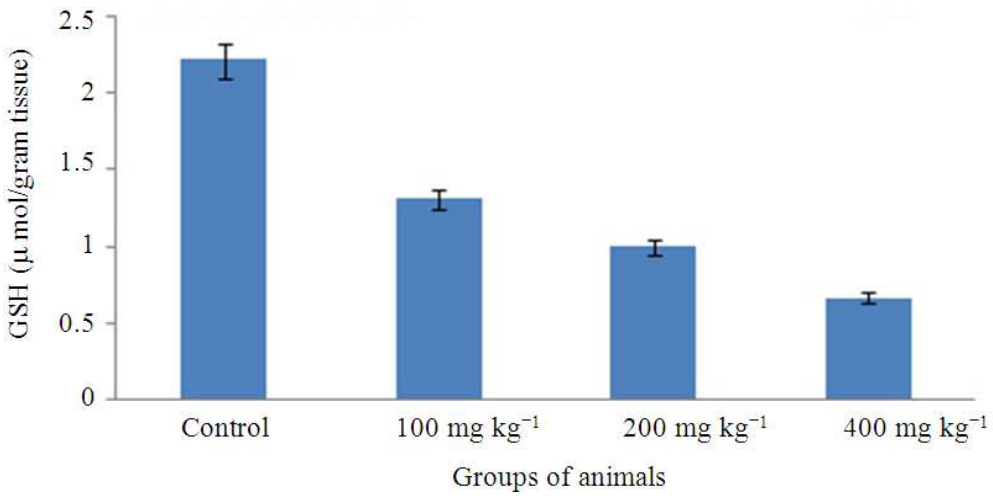

Fig. 3. GDH levels in lung homogenates of animals fed with different dosages of $\mathrm{ZnO}$ nanoparicles

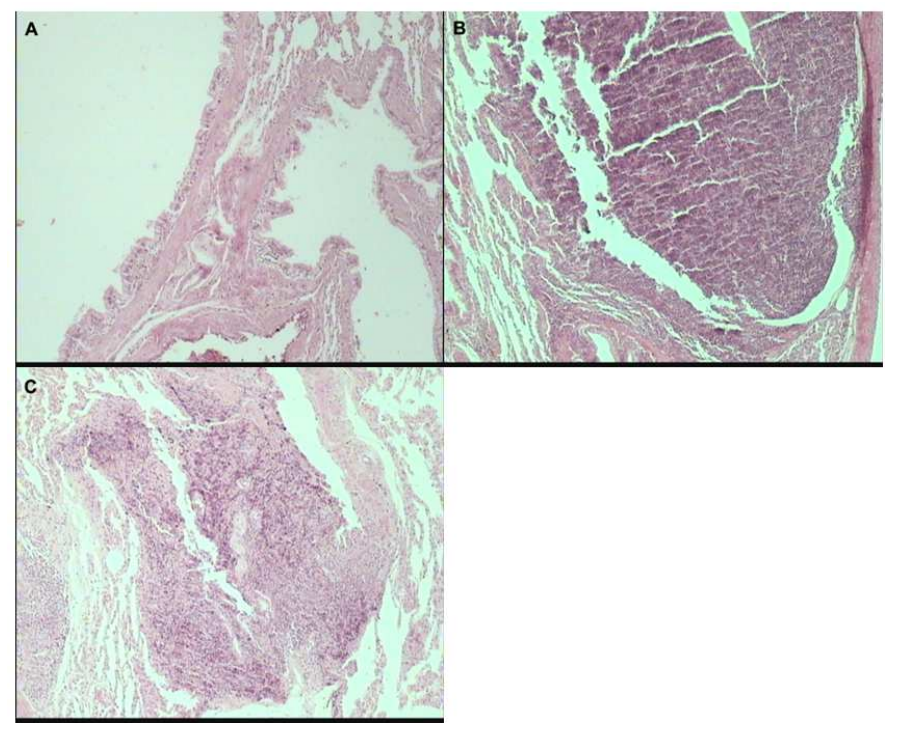

Fig. 4. H\&E stained sections of normal and $\mathrm{ZnO}$ treated rats. (A) Normal lung in group control indicates no sign of inflammation and composed of ciliated epithelial cells and goblet cells. (B) Bronchiolitis in Zno treated animals accompanied with the penetration of lymphocytes in to and around bronchials. (C) Chronic necrotic bronchialitis (all pictures are representative of rats in all groups) 
Ataollah Shokouhian et al. / American Journal of Pharmacology and Toxicology 8 (4): 148-154, 2013

Table 1.Effect of oral administration of different concentration of $\mathrm{ZnO}$ nanoparticles on serum inflammatory markers level and LDH concentration in serum and on congestion and vasculitis in lung tissue. The astric indicates the significant difference between the control $(\mathrm{P}<0.05)$ and the high dose group

\begin{tabular}{lllll}
\hline Parameters & Control & $100 \mathrm{mg} \mathrm{kg}^{-1}$ & $200 \mathrm{mg} \mathrm{kg}^{-1}$ & $400 \mathrm{mg} \mathrm{kg}^{-1}$ \\
\hline TNF- $\alpha(\mathrm{pg} / \mathrm{mL})$ & $256.3 \pm 7.3$ & $346.5 \pm 4.3$ & $389.8 \pm 9.7$ & $465.7 \pm 4.6$ \\
IL-6 $(\mathrm{pg} / \mathrm{ml})$ & $29.1 \pm 2.1$ & $36.5 \pm 3.2$ & $45.6 \pm 2.7$ & $56.5 \pm 2.6$ \\
LDH concetration $(\mathrm{pg} / \mathrm{mL})$ & $335.3 \pm 7.3$ & $456.5 \pm 12.1$ & $511.6 \pm 13.6^{*}$ & $590.4 \pm 13.9^{*}$ \\
LDH activity (IU/L) & $40.1 \pm 4.3$ & $66.5 \pm 4.9$ & $75.6 \pm 6.7$ & $89.5 \pm 5.6^{*}$ \\
Congestion of lung tissue & N/A & $1.00 \pm 0.316$ & $0.6 \pm 0.245$ & $2.00 \pm 0.447^{*}$ \\
Vasculitis & N/A & $1.00 \pm 0.316$ & $1.40 \pm 0.245$ & $2.20 \pm 0.374^{*}$ \\
\hline
\end{tabular}

The GSH levels in lung homogenates of animals fed with different dosages of $\mathrm{ZnO}$ nanoparticles were reduced significantly. The reduction of GSH levels correlated closely with the ascending concentration of $\mathrm{ZnO}$ nanoparticle in treated rats (Fig. 3).

Damages in lung tissue was accompanied with hyperemia in 3 level (mild, moderate, high) and bleeding, atelectasis, light emphysema, lymphocytic perivasculitis and peribronchiolitis in intensive level, pneumonia and increased secretion of ganglions into bronchial.

In group one (low dose), only $20 \%$ of the population showed congestion at mild level and the difference was significant with the control group $(\mathrm{p}<0.05)$. In group two (middle dose), showed $60 \%$ of the population developed moderate congestion. Whereas, in group three (high dose), all rats showed congestion at different degrees as follows; $20 \%$ of the population with moderate congestion, $40 \%$ with mild congestion and $40 \%$ with high congestion. Control group did not show any hyperemia. There was a significant difference between the control and groups 1, 2 and 3. $(\mathrm{p}<0.05)$. Lung damages included hyperemia in 3 level (mild, moderate, high) and bleeding, atelectasis, light emphysema, pribronchiolitis, perivasculitis of lymphocyte in intensive level, pneumonia and increased secretion of exudates into bronchial (Table 1).

\subsection{Statistical Analyse of Perivasculitis and Pribronchiolitis}

In low dose group, $60 \%$ of animals showed prevasculitis and peribronchiolitis in mild level, whereas $20 \%$ of animals showed high level of prevasculitis. Twenty percent of animals' showed no damages. In group two (middle dose), $60 \%$ of animals showed perivasculitis and peribronchiolitis at moderate level. In group 3 (high dose), $20 \%$ of animals showed mild perivasculitis and peribronchiolitis, $40 \%$ of animals showed moderate level and $40 \%$ showed high level of perivasculitis and peribronchiolitis. Control group showed no sign of perivasculitis and peribronchiolitis.
There was a significant difference between all groups as compared to the control group $(\mathrm{p}<0.05)$ (Table 1).

\subsection{Histopathology}

One of the most striking pathological effects of exposure to $\mathrm{ZnO}$ nanoparticles was penetration of lymphocytes in to bronchial and its surrounding area. The normal bronchiolar epithelium is mainly composed of ciliated epithelial cells and goblet cells (Fig. 4A), ZnO nanoparticles induced interstitial fibrosis, contraction and atelectasis of parenchymal lung tissue which was obvious as both gross lesions and in histological sections (Fig. 4B). Oral administration of $\mathrm{ZnO}$ nanoparticle also induced patterns of chronic necrotic bronchiolitis and excretion of exudates (Fig. 4C).

\section{DISCUSSION}

In this study we examined the effect of oral administration of three doses of $\mathrm{ZnO}$ nanoparticle on lung tissue. The results indicate that $\mathrm{ZnO}$ nanoparticles induce dose-dependent cytotoxicity on lung tissue and cause cellular membrane leakage as manifested by reduced GSH levels and increased LDH levels. In the mean time, $\mathrm{ZnO}$ nanoparticles significantly elevate inflammatory cytokine levels including TNF- $\alpha$ and IL-6 in rat serums compared to control group. Levels of $\mathrm{IgG}$ were significantly elevated as well.

Tsou et al. (2010) elucidated that $\mathrm{ZnO}$ nanoparticle concentrations of $\leq 3 \mu \mathrm{g} \mathrm{mL}{ }^{-1}$ resulted in increased cell proliferation, while those of $\leq 45 \mu \mathrm{g} \mathrm{mL}^{-1}$ caused dosedependent increases in oxidized glutathione levels. Nano-ZnO particles induced a dose dependent increase in the expression of the Intercellular Adhesion Molecule (ICAM-1) protein, an indicator of vascular endothelium inflammation and caused marked increases in NF- $\kappa \mathrm{B}$ activity. Moreover, TNF- $\alpha$ induced ICAM-1 expression in a dose dependent manner. These finding shows the synergistic effects of $\mathrm{ZnO}$ nanoparticles and TNF- $\alpha$ on elevation of ICAN-1. 
In addition to the effects of $\mathrm{ZnO}$ nanoparticles on cytokines and $\operatorname{IgG}$ levels, other studies have also reported that zinc oxide nanoparticles were highly fibrogenic and caused an eosinophil exudates into the bronchoalveolar lavage after direct exposure by instillation of nanoparticles (Cho et al., 2010). They have reported that chronic phase of pulmonary fibrosis was associated with increased myofibroblast accumulation of growth factors accompanied with up-regulation of serum $\mathrm{IgE}$. It has also been reported that oral administration of high doses of $\mathrm{ZnO}$ nanoparticles causes histopathological changes in liver and heart tissues (Ghorbani et al., 2013).

The result of present study confirmed that $\mathrm{ZnO}$ nanoparticles cause mild to intensive disorders on the lung tissue in all treated groups by oral gavages. Sayes et al. (2007) demonstrated that the exposure to $\mathrm{ZnO}$ nanoparticles in rat after 7 days is accompanied with signs of toxicity including the increased level of $\mathrm{LDH}$ enzyme, inflammation and increasing the number of neutrophils in blood. Yildirimer et al. (2011) also reported that the toxicity of $\mathrm{ZnO}$ nanoparticles in rat is accompanied with signs of toxicity including the appearance of inflammation, anemia, lowering the body weight and thickening the parapet alveolus in lung. Vandebriel and De Jong (2012) investigated the toxicity effects of $\mathrm{ZnO}$ nanoparticles in rat by oral administration of this nanoparticle which resulted in enhancement of phagositosis by macrophage in abdominal cavity, causing lymphocytic perivasculitis and pribronchiolitis and interstitial pneumonia. It is also documented that $\mathrm{ZnO}$ nanoparticles could elevate the level of $\mathrm{LDH}$ and induce inflammation and apoptosis (Song et al., 2010; Valdiglesias et al., 2013). It appears that the toxicity effects of roller shape Zno nanoparticle is more than the spherical shape particles (Lee et al., 2008). Administration of $10 \mathrm{mmol} / \mathrm{L}$ of $\mathrm{ZnO}$ nanoparticles could cause necrosis and apoptosis in $75 \%$ of cells (Reddy et al., 2007; Jeng and Swanson, 2006). Therefore, $\mathrm{ZnO}$ nanoparticles pose an extraordinary and substantial hazard to the lungs and health precautions to those who are in close contact with this material especially in industrial cities and factories.

\section{CONCLUSION}

In this study, we demonstrated the ability of $\mathrm{ZnO}$ NPs to exert its cytotoxicity effects on lung tissue after oral administration of nanoparticles. We concluded that administration of $\mathrm{ZnO}$ nanoparticles in high dose could cause undesirable effects on lung tissue along with damages to hepatocytes and elevation the level of $\mathrm{LDH}$ enzyme. The increasing doses of nanoparticles could cause significant damages to the lung tissue and to increase LDH, IgG, TNF- $\alpha$ and IL- 6 and emphasizes that exposure to high concentration of $\mathrm{ZnO}$ could cause irreversible damages to different organs including lung and threaten the human health. This finding could be important as a health hazard to those who are in continuous exposure to $\mathrm{ZnO}$ nanoparticles.

\subsection{Competing Interests}

The authors declare that they have no competing financial interests.

\subsection{Authors' Contributions}

SS, AS and MG provided key intellectual input in the conception and design of these studies, performed experiment and aided in the writing of this manuscript. MSA analyzed data and contributed to the writing of the manuscript.

\section{ACKNOWLEDGEMENT}

We would like gratefully to thank all those who helped us in this study.

\section{REFERENCES}

Chen, S., Z. Peng, X. Wang and X. Cheng, 2010. The effect of nano- $\mathrm{ZnO}$ on corona aging and photo aging in low-density polyethylene. IEEJ Trans. Electr. Electron. Eng., 6: 7-13. DOI: 10.1002/tee.20600

Cho, W.S., R. Duffin, C.A. Poland, S.E. Howie and W. Macnee et al., 2010. Metal oxide nanoparticles induce unique inflammatory footprints in the lung: Important implications for nanoparticle testing. Environ. Health Perspect., 118: 1699-1706. DOI: 10.1289/ehp.1002201, PMID: 20729176

Demming, A., 2013. Multitasking in nanotechnology. Nanotechnology, 7: 220201-220201. PMID: 23651791

Dubois, L.H. and R.G. Nuzzo, 1992. Synthesis, structure and properties of model organic surfaces. Ann. Rev. Phys. Chem., 60: 437-463. DOI: 10.1146/annurev.pc.43.100192.002253

Feron, O., 2009. Pyruvate into lactate and back: From the Warburg effect to symbiotic energy fuel exchange in cancer cells. Radiother. Oncol., 92: 329-333. DOI: 10.1016/j.radonc.2009.06.025, PMID: 19604589 
Ghorbani, M., S. Soheili, S. Moradhaseli and A. Shokouhian, 2013. Histopathological effects of $\mathrm{ZnO}$ nanoparticles on liver and heart tissues in wistar rats. Adv. Biores., 4: 83-88.

Golovko, D.S., R. Munoz-Espi and G. Wegner, 2007. Interaction between poly(styrene-acrylic acid) latex nanoparticles and zinc oxide surfaces. Langmuir, 27: 3566-3569. DOI: 10.1021/la0632880

Jeng, H.A. and J. Swanson, 2006. Toxicity of metal oxide nanoparticles in mammalian cells. J. Environ. Sci. Health Tox Hazard Subst Environ Eng., 41: 2699-2711. PMID: 17114101

Johnston, H.J., G. Hutchison, F.M. Christensen, S. Peters and H.S. Stone et al., 2010. A review of the in vivo and in vitro toxicity of silver and gold particulates: Particle attributes and biological mechanisms responsible for the observed toxicity. Crit Rev. Toxicol., 40: 328-346. DOI: 10.3109/10408440903453074, PMID: 20128631

Kaden, J., 2007. IL-6 determination in serum of kidney graft recipients by a new bedside test: Its diagnostic relevance. Transplant Proc., 39: 511-513. DOI: 10.1016/j.transproceed.2006.12.015

Koeneman, B.A., Y. Zhang, P. Westerhoff, Y. Chen and J.C. Crittenden, 2010. Toxicity and cellular responses of intestinal cells exposed to titanium dioxide. Cell Biol. Toxicol., 26: 225-238. DOI: 10.1007/s10565-009-9132-z

Lee, J., B.S. Kang, B. Hicks, T.F. Chancellor and B.H. Chu et al., 2008. The control of cell adhesion and viability by zinc oxidenanorods. Biomaterials, 29: 3743-3749. DOI: 10.1016/j.biomaterials.2008.05.029

Li, Q., C. Shui-Lin and J. Wan-Chao, 2007. Durability of nano $\mathrm{ZnO}$ antibacterial cotton fabric to sweat. J. Applied Polymer Sci., 103: 412-412. DOI: 10.1002/app. 24866

Masciangioli, T. and W.X. Zhang, 2003. Environmental technologies at the nanoscale. Environ. Sci. Technol., 1: 102A-108A. PMID: 12666906

Matsuyama, K., N. Ihsan, K. Irie, K. Mishima and T. Okuyama et al., 2013. Bioimaging application of highly luminescent silica-coated $\mathrm{ZnO}$-nanoparticle quantum dots with biotin. Colloid Interface Sci., 1: 19-25. DOI: 10.1016/j.jcis.2013.02.047
Moron, M.S., J.W. Depierre and B. Mannervik, 1979. Levels of glutathione, glutathione redoctase and glutathione S-transferase activities in rat lung and liver. Bochim. Bophys. Acta, 582: 67-78. DOI: 10.1016/0304-4165(79)90289-7

Reddy, K.M., K. Feris, J. Bell, D.G. Wingett and C. Hanley et al., 2007. Selective toxicity of zinc oxide nanoparticles to prokaryotic and eukaryotic systems. Applied Phys. Lett., 90: 2139021-2139023. PMID: 18160973

Sayes, C.M., K.L. Reed and D.B. Warheit, 2007. Assessing toxicity of fine and nanoparticles: Comparing in vitro measurements to in vivo pulmonary toxicity profiles. Toxicol. Sci., 97: 163180. DOI: $10.1093 /$ toxsci $/ \mathrm{kfm} 018$

Song, W., J. Zhang, J. Guo, J. Zhang and F. Ding, 2010. Role of the dissolved zinc ion and reactive oxygen species in cytotoxicity of $\mathrm{ZnO}$ nanoparticles. Toxicol. Lett., 15: 389-397. DOI: 10.1016/j.toxlet.2010.10.003, PMID: 20934491

Tsou, T.C., S.C. Yeh, F.Y. Tsai, H.J. Lin and T.J. Cheng et al., 2010. Zinc oxide particles induce inflammatory responses in ascular endothelial cells

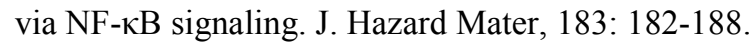
DOI: 10.1016/j.jhazmat.2010.07.010

Valdiglesias, V., C. Costa, G. Kilic, S. Costa and E. Pasaro et al., 2013. Neuronal cytotoxicity and genotoxicity induced by zinc oxide nanoparticles. Environ. Int., 55: 92-100. DOI: 10.1016/j.envint.2013.02.013

Vandebriel, R.J. and W.H. De Jong, 2012. A review of mammalian toxicity of $\mathrm{ZnO}$ nanoparticles. Nanotechnol. Sci. Applic., 5: 61-71. DOI: 10.2147/NSA.S23932

Yildirimer, L., N.T.K. Thanh, M. Marilena Loizidou and A.M. Seifalian, 2011. Toxicology and clinical potential of nanoparticles. Nano Today, 6: 585-607. DOI: 10.1016/j.nantod.2011.10.001 